\title{
Genome restructuring in rye affects the expression, organization and disposition of homologous rDNA loci
}

\author{
Ana D. Caperta ${ }^{1,2, *}$, Nuno Neves ${ }^{1,2}$, Leonor Morais-Cecílio ${ }^{1}$, Rui Malhó ${ }^{3}$ and Wanda Viegas ${ }^{1}$ \\ ${ }^{1}$ Secção de Genética, Departamento de Botânica e Engenharia Biológica, Instituto Superior de Agronomia, Tapada da Ajuda, 1349-017 Lisboa, \\ Portugal \\ 2Departamento de Ciências Biológicas e Naturais, Universidade Lusófona de Humanidades e Tecnologias, Campo Grande 376, $1749-042$ Lisboa, \\ Portugal \\ 3Departamento de Biologia Vegetal, Faculdade de Ciências de Lisboa, Bloco C2, Campo Grande, 1749-016 Lisboa, Portugal \\ *Author for correspondence (e-mail: anadelaunay@isa.utl.pt)
}

Accepted 7 May 2002

Journal of Cell Science 115, 2839-2846 (2002) (C) The Company of Biologists Ltd

\begin{abstract}
Summary
The standard rye cultivar 'Imperial' and a structural variant carrying an intact $1 \mathrm{R}$ chromosome and two telocentric 1R chromosomes (short and long arms) were used to investigate expression patterns of homologous rDNA loci, and the influence of chromosome structural change on their interphase organisation and relative disposition. Sequential silver staining and in situ hybridization with the rDNA probe pTa71, established a correspondence between the expression and organization patterns of rDNA domains in metaphase and interphase cells. In most cells of the cultivar Imperial, nucleolar organizer region (NOR) silver staining on metaphase chromosomes with equivalent numbers of rDNA genes revealed a size heteromorphism between homologous
\end{abstract}

rDNA loci, resulting from their differential expression. NOR heteromorphism in the structural variant line was significantly reduced. The preferential activity of one NOR over its homologue was found to be random within cells and independent of parental origin. Nucleotypic modifications mediated by changes in the $1 \mathrm{R}$ chromosome structure include increased proximity between homologous rDNA loci in interphase, and an increase in the frequency of cells with intra-nucleolar ribosomal condensed chromatin. These results seem to indicate a 'sequence recognition' process for the regulation of homologous loci.

Key words: Homologous gene expression, rDNA topology, Chromosome structure, Telocentric chromosomes, Rye

\section{Introduction}

Chromatin topology plays a major role in the arrangement of genes within the nucleus, and has been widely correlated with gene expression patterns and cell differentiation (Bridger and Bickmore, 1998; Croft et al., 1999; Csink and Henikoff, 1998). During interphase, when genes are actively transcribed, chromosomes tend to occupy specific non-random nuclear territories in both animals (Bridger et al., 2000; Croft et al., 1999) and plants (Abranches et al., 1998; Heslop-Harrisson, 2000; Morais-Cecílio et al., 1996).

A number of studies have examined the organisation of active and inactive genes of the same locus during interphase, using ribosomal chromatin as an experimental model (Junera et al., 1997; Leitch et al., 1992; Rawlins and Shaw, 1990; Robert-Fortel et al., 1993; Roussel et al., 1996). The rRNA genes occur in tandem arrays at multimegabase loci known as the nucleolar organizer regions (NORs). The active ribosomal genes, which usually give rise to a visible secondary constriction on metaphase chromosomes, can be detected by a specific silver staining technique (Ag-staining), which allows the visualization of Ag-NORs that were transcribed in the previous interphase (Hubbell, 1985; Jimenez et al., 1988; Morais-Cecilio et al., 2000; Robert-Fortel et al., 1993). This technique is based on the detection of a set of argyrophilic protein markers associated with active ribosomal genes that reduce the silver under acidic conditions and are found in the nucleoli during interphase (Goodpasture and Bloom, 1975;
Roussel et al., 1996; Zurita et al., 1998). In plants, the usual pattern of active NORs detected by FISH is described as "intranucleolar labelled structures that emanate from perinucleolar heterochromatin sites' (Delgado et al., 1995; Leitch et al., 1992; Rawlins and Shaw, 1990; Shaw et al., 1993). This pattern is in agreement with the current model of NOR chromatin organisation, which proposes that a subset of rRNA genes is packaged into heterochromatin, and thus is inaccessible to the transcription machinery, and that another fraction is euchromatic and transcribed (Carmo-Fonseca et al., 2000).

In actively dividing cells of most plant species the number of copies of rRNA genes is several times higher than in most animals, although the numbers of active genes inside the nucleolus are similar in both cell types (González-Melendi et al., 2001). Furthermore, in most plant species the number of active rRNA genes is very small, as recently demonstrated in Pisum sativum, where only about $5 \%$ of the units are transcribed (González-Melendi et al., 2001). Thus, a diminutive fraction of rRNA genes from only one locus appears to be sufficient to supply all the ribosomal machinery of a cell. Even so, homologous NORs usually have identical behaviour in terms of their expression, and consequently both are either transcribed or silenced. Several attempts, using in situ hybridization with rDNA probes in various diploid species with only one pair of homologous NORs, have shown a direct correlation between the number of ribosomal cistrons in each NOR and its level of transcription (Zurita et al., 1997; Zurita 
et al., 1998; Zurita et al., 1999). However, the relative activity of homologous loci with similar numbers of ribosomal cistrons has not yet been investigated. This is probably due to methodological constraints, as the evaluation of rRNA gene activity is usually performed in highly condensed metaphase NORs.

The aim of the present study was to investigate the expression and organization patterns of homologous NORs in rye with equivalent numbers of rRNA genes. Expression patterns were characterized by silver staining in distended chromosomes that allowed the discrimination between dominant and under-dominant homologous rDNA loci. A structural variant rye line carrying an intact $1 \mathrm{R}$ chromosome and two telocentric 1R chromosomes (short and long arms), was also used to disclose any possible effect of parental imprinting on inter-homologous NOR dominance. The effects of nucleotypic changes, in terms of the chromosome structural variant, were also analysed. This was done using FISH with the pTa71 probe to better understand the modulation of RNA gene expression patterns between homologous loci.

\section{Materials and Methods}

\section{Plant material}

The plant material used was rye, Secale cereale L. In addition to the standard cultivar 'Imperial', a double monotelosomic line for the nucleolar chromosome $1 \mathrm{R}$ was also used. This line was produced by controlled reciprocal crosses between euploid Imperial and a double ditelosomic 1R rye line 'Heines Hellkorn' (kindly provided by Prof. Zeller, Munich). In the double ditelosomic line, both arms of chromosome 1R are present as telocentric chromosomes $\left(1 \mathrm{R}^{\mathrm{S}} 1 \mathrm{R}^{\mathrm{S}} 1 \mathrm{R}^{\mathrm{L}} 1 \mathrm{R}^{\mathrm{L}}\right)$. In the double monotelosomic line, there is one standard $1 \mathrm{R}$ and two telocentric chromosomes derived from each arm of the $1 \mathrm{R}$ chromosome, which will be referred to as $1 \mathrm{R} 1 \mathrm{R}^{\mathrm{S}} 1 \mathrm{R}^{\mathrm{L}}$.

\section{Seed treatments}

Seeds were germinated in water for 3 days at $24^{\circ} \mathrm{C}$. Root-tips from cultivar Imperial were then cold treated $\left(30\right.$ hours at $\left.0^{\circ} \mathrm{C}\right)$, colchicine treated in a $0.1 \mathrm{mg} / \mathrm{ml}$ solution during 4 hours at $22^{\circ} \mathrm{C}$, or placed in a $1 \mathrm{ng} / \mathrm{ml}$ oryzalin solution for 3 hours at $22^{\circ} \mathrm{C}$. From each numbered seedling, three root-tips were excised so that at least one root-tip per seedling was used for each of the three c-mitotic pre-treatments. For the $1 \mathrm{R} 1 \mathrm{R}^{\mathrm{S}} 1 \mathrm{R}^{\mathrm{L}}$ line, only colchicine was used. All root-tips were fixed in $3: 1(\mathrm{v} / \mathrm{v})$ absolute ethanol/glacial acetic acid for 24 hours at room temperature and stored at $-20^{\circ} \mathrm{C}$.

\section{Silver staining}

The fixed material was transferred to a fresh solution of FAA $(50 \%$ ethanol:37\% formaldehyde:glacial acetic acid, 18:1:1, v/v) for 3 days at $-20^{\circ} \mathrm{C}$. Chromosome preparations were produced by enzymatic digestion, as described previously (Schwarzacher et al., 1989), and squashes were made in $45 \%$ acetic acid. Silver staining followed a technique described elsewhere (Neves et al., 1995).

\section{Fluorescence in situ hybridisation (FISH) and imaging}

Sequential FISH was performed on the same chromosome preparations from cells previously silver stained, without removing the silver labelling. The FISH procedure followed that described previously (Morais-Cecílio et al., 2000), using the DNA probe pTa71. This probe is a $9 \mathrm{~kb} E c o$ RI fragment of the ribosomal DNA from wheat (Triticum aestivum), containing the $5.8 \mathrm{~S}, 18 \mathrm{~S}, 25 \mathrm{~S}$ and nontranscribed spacer sequences. DNA was counterstained with DAPI

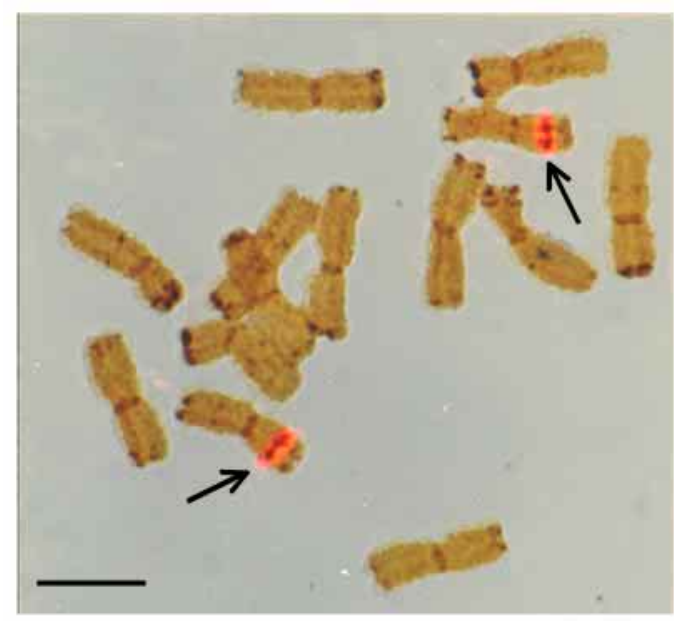

Fig. 1. A cold-treated meristematic metaphase cell of rye showing the co-localization of the rDNA sites detected by in situ hybridization (in red) and the silver stained Ag-NORs (dark brown). On the condensed NORs (arrows), the silver signal reveals the previous expression of rRNA genes, whereas the two hybridization sites of identical size demonstrate that the two rDNA loci have equivalent numbers of ribosomal cistrons. Bar, $5 \mu \mathrm{m}$.

(4',6 diamino-2-phenylindole dihydrochloride). Preparations were observed by epifluorescence microscopy (Leitz Biomed), with the appropriate filters. Images were collected using an AxionCam digital camera (Zeiss) controlled by AxioVision 3.0, and processed using the Adobe Photoshop 5.0 (Adobe Systems, Mountain View, CA).

\section{Confocal microscopy and imaging}

To analyse rDNA organization at interphase, root-tips were digested using the same enzymatic mixture as before, followed by dissection in $45 \%$ acetic acid under a stereomicroscope. The root-cap and nondividing parts of the root were discarded, and the remaining (mainly meristematic) cells were then pipetted onto ethanol-cleaned eight-well glass slides (ICN Biochemicals), and left to air dry. This procedure avoids squashing and preserves the architecture of the nucleus. Following in situ hybridisation interphase cells were imaged with an MRC-600 confocal scanning laser microscope equipped with a 15 mW krypton-argon laser (Bio-Rad Microscience, Hemel Hempstead, UK). The microscopy data were transferred to NIH image (a public domain program for Macintosh available via ftp from ftp://zippy.nimh.nih.gov) and processed using the Adobe Photoshop 5.0 (Adobe Systems).

\section{Results \\ Different c-mitotic treatments induce differential NOR condensation at metaphase}

The three pre-treatments were performed on individual roottips from each of five cultivar Imperial seedlings. A comparison of treatments between individual root-tips from the five different seedlings indicated no significant differences $(P<0.001)$ based on inter-individual variability.

To evaluate the level of expression of each rDNA locus, the length of each NOR was compared with the length of the satellite (chromosome region located on the telomeric side of the secondary constriction). At the first level of discrimination for NOR size we considered that a secondary constriction is condensed (Fig. 1) when it is smaller or has the same length 


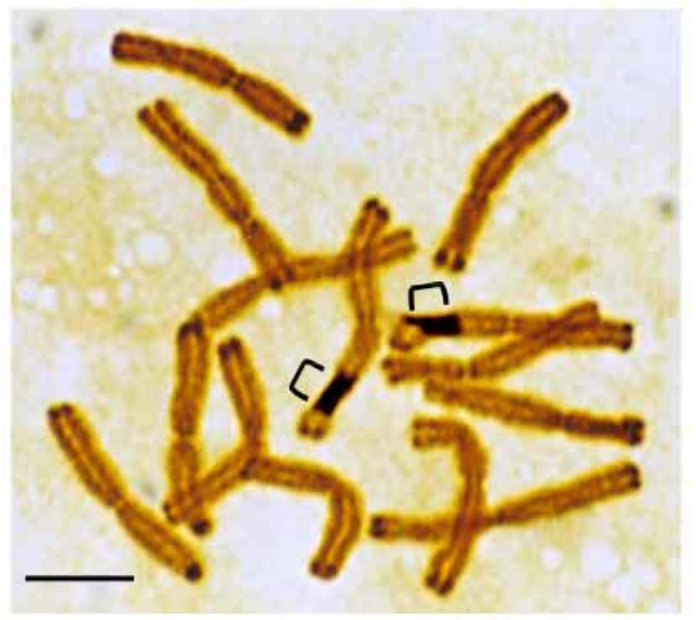

Fig. 2. A colchicine-treated meristematic metaphase cell of rye showing two distended and homomorphic Ag-NORs (brackets) detected by silver staining. Bar, $5 \mu \mathrm{m}$.

as the satellite, and that it is distended (Fig. 2) when it is longer than the satellite. As shown in Table 1, there is a difference in NOR condensation according to the treatment applied. In the cold-treated root tips the overall frequency of condensed NORs is high, whereas using colchicine and oryzalin at $22^{\circ} \mathrm{C}$, the majority of NORs were of the distended type (Table 1). No apparent difference was obtained with oryzalin or colchicine, and colchicine was chosen as the preferred treatment thereafter.

\section{Homologous NORs with equivalent numbers of rRNA genes show differential expression}

In situ hybridisation with the rDNA probe pTa71 was used to estimate the number of ribosomal cistrons present in a NOR, based on the strength of the hybridisation signal, an approach followed by several authors (Leitch and Heslop-Harrison, 1992; Mandrioli et al., 1999; Mellink et al., 1994; Suzuki et al., 1990; Zurita et al., 1998; Zurita et al., 1999). In metaphase cells from cold-treated root-tips of cultivar Imperial the pTa71 detected by FISH showed equivalent signals (in size and intensity) in homologous NOR loci of the condensed type. This result indicates that homologous rDNA loci have similar numbers of genes. When silver staining and FISH results were simultaneously observed in condensed NORs, the signals were found to be largely overlapping (Fig. 1).

A comparison of homologous Ag-NOR sizes was performed in each cell, by observing Ag-NORs with similar lengths (Figs 1, 2) or with distinct dimensions (Fig. 3). Ag-NORs were considered differently sized (i.e. heteromorphic, resulting from differential rDNA expression) when differing by at least $25 \%$ in length. The frequency of cells with heteromorphic Ag-NORs was much higher after chemical treatment compared with cold treatment (Table 1). In addition, the structural resolution of the NOR loci was improved on metaphase chromosomes with distended secondary constrictions. Sequential silver staining and FISH with pTa71 revealed a centromere-proximal condensed NOR region, only detected by FISH, whereas the overlapping silver and in situ signals are more distally located in the NOR region that decondenses progressively towards the satellite (Fig. 3).
Fig. 3. Colchicine-treated meristematic metaphase cells of rye. (a) Simultaneous visualization of chromatin (DAPI staining in blue) and of the rDNA hybridization sites (red) reveals the presence of two NORs exhibiting a centromere-proximal block of rDNA followed by a ribosomal chromatin filament towards the satellite (brackets). Note the clear length differences between the decondensed regions of the two homologous rDNA loci. (b) The
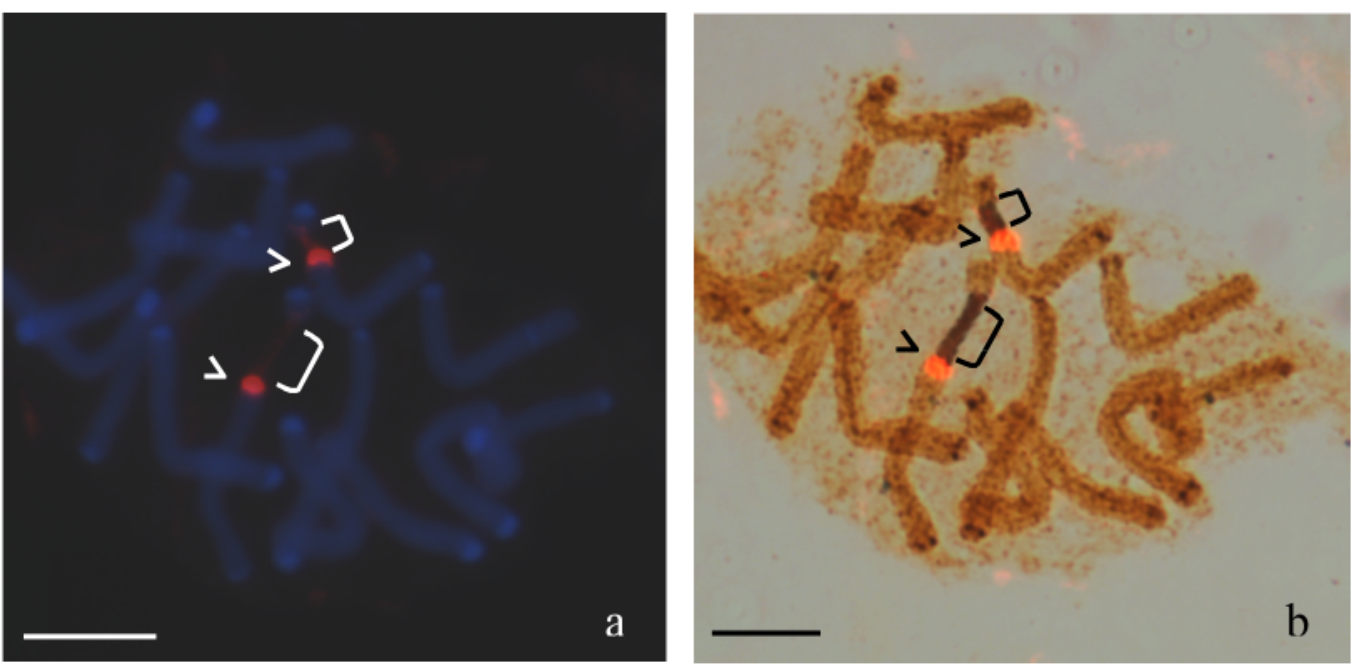

the in situ hybridization and the silver staining signals shows that the Ag-positive rDNA fraction is found only coincident with the distended ribosomal chromatin revealed by FISH (compare with a). Bar, $5 \mu \mathrm{m}$.

Table 1. Frequency of Ag-NOR condensation and heteromorphic Ag-NOR pairs in c-metaphase cells

\begin{tabular}{|c|c|c|c|c|}
\hline C-mitotic treatments & $\begin{array}{c}\text { Condensed } \\
\text { Ag-NORs }(\%)\end{array}$ & $\begin{array}{c}\text { Distended } \\
\text { Ag-NORs }(\%)\end{array}$ & $\begin{array}{c}\text { Cells with heteromorphic } \\
\text { Ag-NORs }(\%)\end{array}$ & $\begin{array}{c}\text { No. of } \\
\text { cells analysed }\end{array}$ \\
\hline Cold $\left(0^{\circ} \mathrm{C}\right)$ & 91 & 9 & 59 & 58 \\
\hline Oryzalin & 14 & 86 & 92 & 36 \\
\hline Colchicine & 17 & 83 & 94 & 37 \\
\hline
\end{tabular}




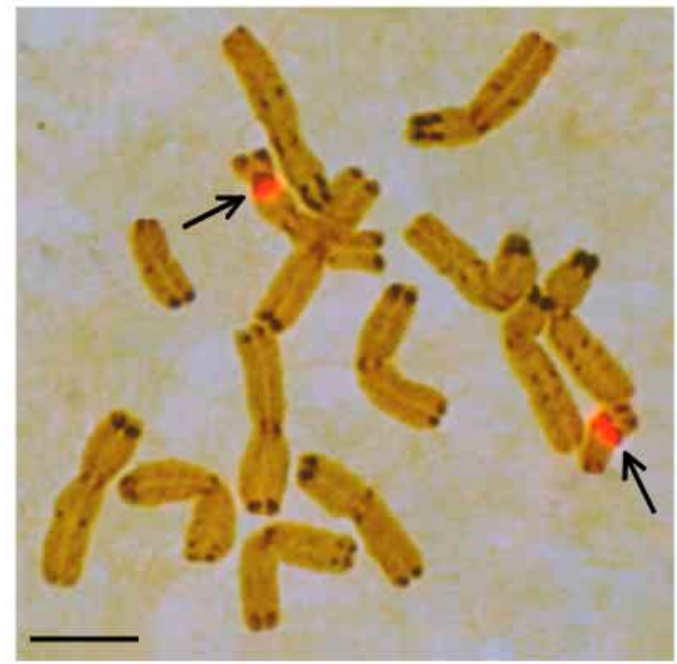

Fig. 4. A colchicine-treated meristematic root-tip metaphase cell of a double monotelosomic line of rye showing both the co-localization of the rDNA sites detected by in situ hybridization (red) and the silver stained Ag-NORs (dark brown). On condensed NORs (arrows), the silver signal reveals the previous expression of rRNA genes, whereas the two hybridization sites of identical size demonstrate that the two rDNA loci have equivalent numbers of ribosomal cistrons. Bar, $5 \mu \mathrm{m}$.

The structure of nucleolar chromosomes affects differential expression between homologous NORs and discloses non-parental imprinting

We investigated the possible influence of NOR bearing chromosome structure on the expression of homologous NORs using the double monotelosomic hybrid rye line $\left(1 \mathrm{R} 1 \mathrm{R}^{\mathrm{S}} 1 \mathrm{R}^{\mathrm{L}}\right)$. In this line, discrimination between rDNA loci of parental origin is easily achieved, through clear NOR-bearing chromosome identification based on chromosome morphology at metaphase. The root-tip cells used were obtained from three different individuals, where cultivar Imperial was the female progenitor in two of them, while the third was produced using cultivar Imperial as the male parent. In situ hybridisation with pTa71 showed that both rDNA loci have similar numbers of rRNA genes (Fig. 4). In colchicine-treated cells, the frequency of metaphases with Ag-NOR heteromorphism is reduced almost to a half $(58 \%)$ in the telosomic compared with the normal line cultivar Imperial (94\%). Furthermore, a random NOR dominance was detected (either the $1 \mathrm{R}-\mathrm{NOR}$ or the $1 \mathrm{R}^{\mathrm{S}}$ NOR dominates in an exact 1:1 proportion; Table 2). There is no preferential expression of a particular NOR over its homologue, neither is there any differential parental effect. To link interphase organisation of rDNA and Ag-NOR heteromorphism, the relative dimensions of the two nucleoli of each nucleus were compared, considering them as heteromorphic when their area differed at least 25\% (Fig. 5). A marked reduction in nucleoli heteromorphism was observed in the telosomic line (52\%) in comparison with cultivar Imperial (71\%; Table 2). It was noticeable that no genotype influence was detected on the relative average frequency of cells with one nucleolus, which was of $80 \%$ for the 1R1R line, and $81 \%$ for $1 \mathrm{R} 1 \mathrm{R}^{\mathrm{S}} 1 \mathrm{R}^{\mathrm{L}}$.
Table 2. Frequency of NOR and nucleoli heteromorphism

\begin{tabular}{|c|c|c|c|}
\hline Genotype & $\begin{array}{r}\text { Cells wit } \\
\mathrm{Ag}-\end{array}$ & $\begin{array}{l}\text { teromorphic } \\
\text { 2s }(\%)\end{array}$ & $\begin{array}{c}\text { Cells with heteromorphic } \\
\text { nucleoli }(\%)\end{array}$ \\
\hline$\overline{1 R 1 R}$ & $94\left(37^{*}\right)$ & \multirow[b]{2}{*}{$\begin{array}{l}1 R>1 R^{S} 29 \\
1 R^{S}>1 R 29\end{array}$} & $71\left(56^{*}\right)$ \\
\hline $1 \mathrm{R} 1 \mathrm{R}^{\mathrm{S}} 1 \mathrm{R}^{\mathrm{L}}$ & $58\left(62^{*}\right)$ & & $52\left(48^{*}\right)$ \\
\hline
\end{tabular}

*Number of cells analysed.

Organisation and relative positioning patterns of homologous rDNA loci at interphase are modified by changes in NOR-bearing chromosome structure

Patterns of rDNA chromatin organization in interphase nuclei were characterized through in situ hybridisation with the pTa71 probe, followed by confocal analysis. Table 3 gives the frequencies of individual rDNA organization patterns classified into three types. In seedlings of cultivar Imperial (either untreated or with colchicine treatment) a few cells showed large perinucleolar knobs without further traces of labelled chromatin within the nucleolus (Type I; Fig. 6a). In most of the cells the pattern is the same as that described previously (Delgado et al., 1995; Leitch et al., 1992), where nuclei exhibited two condensed perinucleolar knobs from which thin rDNA filaments emerge towards the interior of the nucleolus (Type II; Fig. 6b). The perinucleolar rDNA chromatin knobs are localized on the nucleolar surface, positioned in the nuclear pole where DAPI staining shows the chromatin to be more concentrated (Figs 6, 7). At the opposite nucleolar surface, the characteristic blocks of heterochromatin from rye telomeric regions are clearly visible, but knobs of perinucleolar ribosomal chromatin were usually undetectable. No major difference was observed in the frequencies of rDNA organisation patterns in untreated and colchicine-treated roottips of the cultivar Imperial. Therefore, this c-mitotic treatment has no significant influence in the rDNA topology at interphase. In the structural variant line $\left(1 \mathrm{R} 1 \mathrm{R}^{\mathrm{S}} 1 \mathrm{R}^{\mathrm{L}}\right)$, although the majority of rDNA loci belong to Type II, a considerable frequency of NOR loci was detected exhibiting large perinucleolar rDNA knobs and condensed intranucleolar spots (Type III; Fig. 6c). rDNA loci with this type of interphase organization, where thin threads of chromatin link intranucleolar rDNA spots, are usually absent in normal rye lines.

The rDNA loci in interphase root tip cells were also investigated to characterize relative patterns of ribosomal

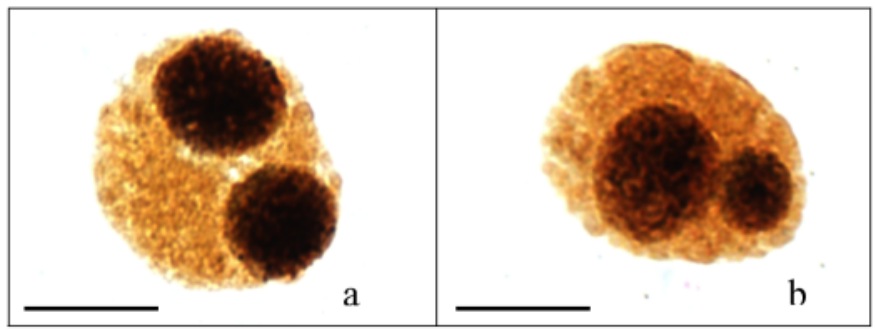

Fig. 5. Meristematic interphase nuclei of rye after silver staining, showing two homomorphic and two heteromorphic nucleoli (a and b, respectively). Bar, $5 \mu \mathrm{m}$. 
Fig. 6. Simultaneous visualization of chromatin (DAPI staining in blue) and rDNA hybridization sites (red) in meristematic interphase nuclei of rye, showing the major patterns of rDNA organization. (a) Type I: condensed perinucleolar knobs (arrows) without any traces of labelled rDNA chromatin inside the nucleolus. (b) Type II: condensed perinucleolar knobs (arrows) with thin filaments of rDNA chromatin towards the interior of the nucleolus
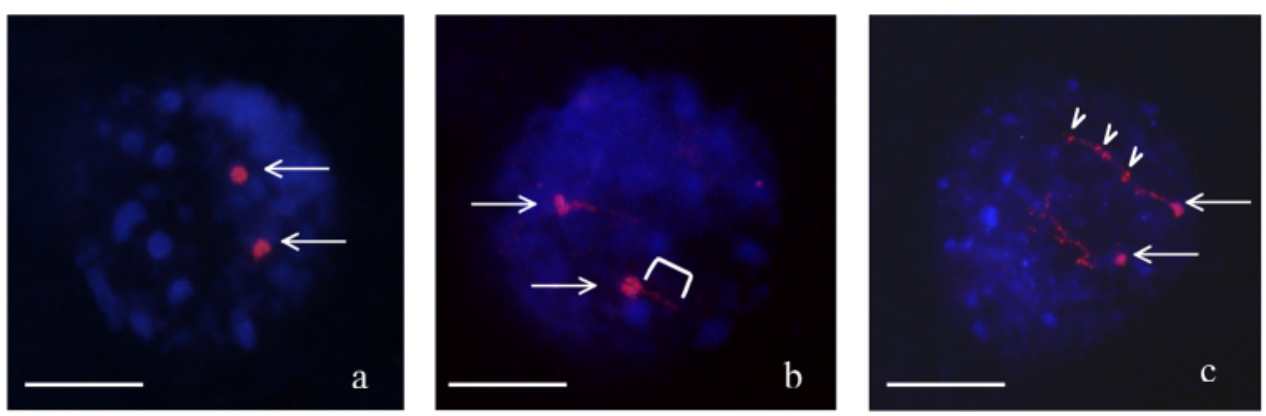

(bracket). (c) Type III: condensed perinucleolar knobs (arrows) with intranucleolar condensed rDNA spots (arrowheads) linked by thin chromatin filaments (hybrid rye line). Bar, $5 \mu \mathrm{m}$. Note that rDNA perinucleolar knobs are usually present on the nuclear hemisphere where DAPI staining is more intense, indicating a higher concentration of chromatin in this pole of the nucleus.

Table 3. Frequency of rDNA organization patterns in interphase nuclei

\begin{tabular}{|c|c|c|c|c|c|}
\hline \multirow[b]{2}{*}{ Genotype } & \multirow{2}{*}{$\begin{array}{l}\text { C-mitotic } \\
\text { treatment }\end{array}$} & \multicolumn{3}{|c|}{$\begin{array}{l}\text { rDNA organization } \\
\text { types }(\%)\end{array}$} & \multirow{2}{*}{$\begin{array}{l}\text { No. of rDNA } \\
\text { loci analysed }\end{array}$} \\
\hline & & I & II & III & \\
\hline \multirow{2}{*}{ 1R1R } & Untreated & 9 & 89 & 2 & 268 \\
\hline & Colchicine & 7 & 93 & 0 & 308 \\
\hline $1 \mathrm{R} 1 \mathrm{R}^{\mathrm{S}} 1 \mathrm{R}^{\mathrm{L}}$ & Colchicine & 2 & 72 & 26 & 184 \\
\hline
\end{tabular}

chromatin distribution between the standard cultivar and in its chromosome structural variant. Interphase cells with a single nucleolus, and without intra-nucleolar condensed spots (Types I and II), were selectively observed to ensure a precise comparison. Separated (Fig. 6a), adjacent (Fig. 7a) and fused (Fig. 7b) rDNA knobs were considered. The results are presented in Table 4 . While in cultivar Imperial only 5\% of interphase cells show both rDNA loci undistinguishable, $24 \%$ of cells in the $1 \mathrm{R} 1 \mathrm{R}^{\mathrm{S}} 1 \mathrm{R}^{\mathrm{L}}$ line exhibit fused rDNA loci, as only one larger single hybridization spot could be observed. The state of the genome, with respect to its nucleolar chromosomes, influences the relative domains of these chromosomes within the nucleus and indicates positional interaction.

\section{Discussion}

The aim of this study was to investigate the relative expression patterns of homologous rDNA loci in rye. We chose RNA genes in order to make a cytological evaluation, and to correlate patterns of expression with chromatin organisation and positioning. Nucleotypic features involved in the modulation of the activity of homologous rDNA loci have been revealed, using rye cultivar Imperial and a structural variant $\left(1 \mathrm{R} 1 \mathrm{R}^{\mathrm{S}} 1 \mathrm{R}^{\mathrm{L}}\right)$ with similar numbers of rRNA genes in homologous NORs.

\section{Structural and functional domains within NORs at} metaphase correspond to rDNA interphase organization In plants, it has been clearly established that interphase patterns of rDNA loci organization detected by FISH are correlated with their activity (Delgado et al., 1995; Leitch et al., 1992; Shaw et al., 1993; Wallace and Langridge, 1971). rRNA gene activity can be revealed by a silver staining technique that allows the detection of metaphase Ag-NORs that were actively
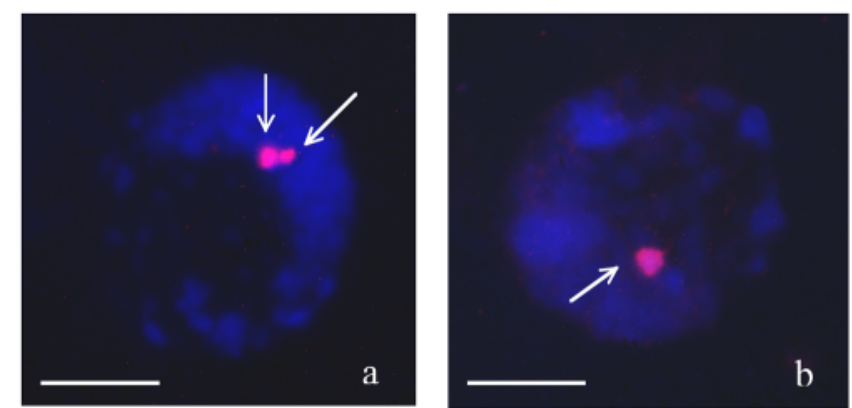

Fig. 7. Simultaneous visualization of chromatin (DAPI staining in blue) and rDNA hybridization sites (red) in meristematic interphase nuclei of rye illustrating the relative positioning rDNA loci.

(a) Adjacent rDNA loci. (b) Fused rDNA loci (hybrid rye line). Bar, $5 \mu \mathrm{m}$. Note that rDNA perinucleolar knobs are usually present on the nuclear hemisphere where DAPI staining is more intense, indicating a higher concentration of chromatin in this pole of the nucleus.

transcribed during the previous interphase (Hubbell, 1985; Jímenez et al., 1988; Zurita et al., 1998). We reported here that, after sequential silver staining and FISH with the rDNA probe pTa71, distended NORs show two different structural and functional domains. These domains involve a condensed subset of rDNA chromatin in the centromere proximal region, without silver staining; and a more distal subset of distended rDNA chromatin co-localised with silver staining. In metaphase NORs, different structural and functional domains have not previously been described, since only condensed NORs have been analysed before, where Ag-staining and labelling with the FISH probe pTa71 are superimposed. Previous studies on rDNA chromatin organization and NOR structure propose that the NOR may include a stronger (darker) stained heterochromatic knob (i.e. a chromomere) in the centromereproximal region (McClintock, 1934). This knob, after further interpretation (Wallace and Langridge, 1971), was thought to

Table 4. Frequency of rDNA distribution patterns in interphase nuclei with one nucleolus

\begin{tabular}{lcccc}
\hline & \multicolumn{3}{c}{$\begin{array}{c}\text { Relative positioning of rDNA } \\
\text { knobs at interphase }(\%)\end{array}$} & $\begin{array}{c}\text { No. of cells } \\
\text { analysed }\end{array}$ \\
\cline { 2 - 4 } Genotype & Separated & Adjacent & Fused & \\
\hline 1R1R & 70 & 25 & 5 & 231 \\
$1 \mathrm{R} 1 \mathrm{R}^{\mathrm{S}} 1 \mathrm{R}^{\mathrm{L}}$ & 59 & 17 & 24 & 294 \\
\hline
\end{tabular}


be composed mainly of inactive ribosomal RNA genes, and the secondary constriction represented the active, transcribed ones. Our experimental approach shows that not only is heterochromatic rDNA always present at the centromere proximal end of the NOR, but it also allowed us to find a correlation between the centromere-proximal rDNA knobs detected in metaphase and the rDNA perinucleolar knobs observed in interphase. These knobs are usually located at the nuclear pole where the centromeres are clustered (Abranches et al., 1998; Anamthawat-Jonsson and Heslop-Harrisson, 1990; Leitch, 2000). Other approaches have shown that only a fraction of rRNA genes at interphase are in an accessible (presumably active) chromatin configuration (Banditt et al., 1999; Conconi et al., 1989; Dammann et al., 1995; GonzálezMelendi et al., 2001). At the whole NOR level, we can conclude that rRNA gene silencing in rye is not fully randomised, as distended metaphase NORs always show the condensed inactive rDNA chromatin in the centromereproximal region. The absence of silver staining in this region indicates that these genes remain largely inactive during the previous interphase, probably due to protein-protein interactions between nearby heterochromatin domains (Carmo-Fonseca et al., 2000; Pluta et al., 1995). C-banding in rye has revealed a heterochromatic band adjacent to the NOR at the centromere-proximal region (Sybenga, 1983), which may therefore influence the organization of the neighbouring rDNA chromatin.

\section{Homologous NORs with equivalent numbers of rRNA genes display different expression patterns}

At metaphase, Ag-NOR size and intensity of the silver staining have been correlated with rRNA gene activity in the previous interphase (Hernandez-Verdun, 1991; Morais-Cecílio et al., 2000; Robert-Fortel et al., 1993; Zurita et al., 1997; Zurita et al., 1998; Zurita et al., 1999). A correlation between the size of the hybridisation signal and the number of rRNA genes present at a NOR has also been described in homologous (Zurita et al., 1998) or non-homologous loci (Leitch and Heslop-Harrison, 1992; Mellink et al., 1994; Suzuki et al., 1990). Using these approaches we demonstrate that homologous NORs with equivalent numbers of genes per locus display differential expression.

Several previous studies on the regulation of rDNA transcription, at both the intra- and interspecific level, point to a model where competition between rDNA loci for essential transcription factors in limiting concentrations seems to be the more consensual explanation for differential activity between different NORs (reviewed by Pikaard, 1999; Pikaard, 2000; Zurita et al., 1998; Zurita et al., 1999). This model implies distinct abilities of different NORs to recruit these transcription factors, based mainly on the number of the rRNA gene units present at an NOR. However, this hypothesis cannot explain our results in rye, because both rDNA loci have equivalent numbers of rDNA units, as shown by the FISH results. This suggests that an alternative hypothesis is required for the mechanism to explain differential NOR expression. In the chromosome structural variant line we observed a significant reduction in the frequency of interphase cells with heteromorphic nucleoli, which is a direct measure of rDNA loci transcription level (Martini and Flavell, 1985), together with a significant decrease in the frequency of metaphase cells with Ag-NOR heteromorphism in comparison with cultivar Imperial. Thus a minor modification in the genomic structure is sufficient to promote significant changes in the relative expression of homologous rDNA loci. It should be stressed that the frequency of heteromorphic NORs is higher than the frequency of heteromorphic nucleoli in each genotype analysed. This apparent discrepancy can be readily explained, since heteromorphic nucleoli were assessed early in the cell cycle $\left(G_{1}\right)$ where nuclei display two nucleoli. Observations of metaphase NOR heteromorphism come from rDNA loci expression during all interphase stages (i.e. $\mathrm{G}_{1}, \mathrm{~S}, \mathrm{G}_{2}$ ).

Differential expression of homologous rDNA loci also raises the question as to the existence or not of any preferential activity of one particular locus over its homologue. Through the use of the $1 \mathrm{R} 1 \mathrm{R}^{\mathrm{S}} 1 \mathrm{R}^{\mathrm{L}}$ line, where the parental origin of the NOR could be clearly identified by chromosome morphology, we were able to detect random differential silencing. There is evidence that each particular NOR retains its relative transcription level between cell divisions (Roussel et al., 1996), although a single rDNA transcription unit may exhibit different expression patterns throughout cell divisions (Damman et al., 1995). The random inter-homologous NOR dominance observed in this work can either result from differential patterns established after each cell division, or from patterns imposed early on in development and then maintained, recalling the cell mosaicism described previously (Platero et al., 1998).

\section{Relative positioning of homologous rDNA loci is correlated with their differential activity}

In a wide range of organisms many types of gene silencing processes appear to involve DNA-DNA interactions between genes at allelic and non-allelic sites (Henikoff, 1997; Kooter et al., 1999; Matzke and Matzke, 1998; Matzke et al., 1994; Wolffe and Matzke, 1999). Here, we show that by modifying the NOR-bearing chromosome structure, the frequency of interphase cells with fused perinucleolar knobs is fivefold higher than in the standard rye cultivar Imperial. Moreover, in $26 \%$ of the interphase cells of the variant structural line we also observed ribosomal intra-nucleolar condensed spots in addition to the already known perinucleolar knobs. Intra-nucleolar condensed spots of rDNA seem to be characteristic of some species, such as hexaploid wheat (Leitch et al., 1992; MoraisCecilio et al., 2000), and rare in other species, such as rye (Delgado et al., 1995; Leitch et al., 1992). These spots, recently referred to as ribosomal heterochromatin (Carmo-Fonseca et al., 2000), were previously interpreted as unexpressed condensed regions that separate transcribing rRNA genes (Leitch et al., 1992).

The observations on the telosomic variant line clearly show a greater proximity of the NORs from $1 \mathrm{R}$ and $1 \mathrm{R}^{\mathrm{s}}$, and fusion between homologous rDNA loci, indicating that rDNA chromatin disposition is modified by this alteration in chromosome structure. Moreover, condensed intra-nucleolar knobs of rDNA chromatin were also observed. This analysis allows us to establish a correlation between NOR disposition and organization patterns, and their differential expression, since Ag-heteromorphism was reduced in the telosomic variant line. 
This greater proximity of homologous rDNA loci can either be due to a more direct recognition between homologous chromosome arms in the nucleus, or derive from modifications to the relative disposition of chromosomes in the haploid complement, due to the presence of telocentric chromosomes. The correlation between NOR closeness and reduction of differential expression between homologous rDNA loci could be explained by differences in the localization of NORs in nuclear domains where transcription factors are unevenly distributed. This hypothesis would imply that when NORs colocalize (as in the variant line) only then are they exposed to the same pool of transcription factors. However, it still remains unclear whether or not transcription factors have any preferential nuclear domains of localization. It is known for example, that transcription sites are not correlated with chromosome territories in wheat nuclei, and show a uniform distribution throughout the nuclear volume (Abranches et al., 1998). Although we cannot discriminate trans-interactions between genes of homologous loci, or make conclusions about regulatory processes, the greater frequency in the intranucleolar rDNA chromatin condensations that we observe in the variant line, where NORs are in closer proximity, may suggest a raised level of 'sensing of homologous sequences' between rDNA loci.

The authors are most grateful to A. Barão for her excellent technical assistance and to Prof. Neil Jones for the enlightening discussions and critical review of the manuscript. The work was supported by Fundação da Ciência e da Tecnologia (Project Praxis/AGR/11171/98).

\section{References}

Abranches, R., Beven, A. F., Aragón-Alcaide, L. and Shaw, P. J. (1998). Transcription sites are not correlated with chromosome territories in wheat nuclei. J. Cell Sci. 143, 5-12.

Anamthawat-Jónsson, K. and Heslop-Harrison, J. S. (1990). Centromeres, telomeres and chromatin in the interphase nucleus of cereals. Caryologia 43, 205-213.

Banditt, M., Koller, T. and Sogo, J. (1999). Transcriptional activity and chromatin structure of enhancer-deleted rRNA genes in Saccharomyces cerevisiae. Mol. Cell. Biol. 19, 4953-4960.

Bridger, M. D. and Bickmore, W. A. (1998). Putting the genome on the map. Trends Genet. 14, 403-409.

Bridger, J. M., Boyle, S., Kill, I. R. and Bickmore, W. A. (2000). Remodelling of nuclear architecture in quiescent and senescent human fibroblasts. Curr. Biol. 10, 149-152.

Carmo-Fonseca, M., Mendes-Soares, L. and Campos, I. (2000). To be or not to be in the nucleolus. Nat. Cell Biol. 2, 107-112.

Conconi, A., Widmer, R., Koller, T. and Sogo, J. (1989). Two different chromatin structures coexist in ribosomal RNA genes throughout the cell cycle. Cell 57, 753-761.

Croft, J. A., Bridger, J. M., Boyle, S., Perry, P., Teague, P. and Bickmore, W. A. (1999). Differences in the localization and morphology of chromosomes in the human nucleus. J. Cell Biol. 145, 1119-1131.

Csink, A. K. and Henikoff, S. (1998). Large scale chromosomal movements during interphase progression in Drosophila. J. Cell Sci. 143, 13-22.

Damman, R., Lucchini, R., Koller, T. and Sogo, J. (1995). Transcription in the yeast rRNA gene locus: distribution of the active gene copies and chromatin structure of their flanking regulatory sequences. Mol. Cell. Biol. 15, 5294-5303.

Delgado, M., Morais-Cecílio, L., Neves, N., Jones, R. N. and Viegas, W. (1995). The influence of B chromosomes on rDNA organization in rye interphase nuclei. Chromosome Res. 3, 487-491.

González-Melendi, P., Wells, B., Beven, A. and Shaw, J. (2001). Single ribosomal transcription units are linear, compacted Christmas trees in plant nucleoli. Plant J. 27, 223-233.

Goodpasture, C. and Bloom, S. E. (1975). Visualization of nucleolar organizer regions in mammalian chromosomes using silver staining. Chromosoma 53, 37-50.

Henikoff, S. (1997). Nuclear organization and gene expression: homologous pairing and long-range interactions. Curr. Opin. Cell Biol. 9, 388-395.

Hernandez-Verdun, D. (1991). The nucleolus today. J. Cell Sci. 99, 465-471.

Heslop-Harrison, J. S. (2000). Comparative genome organization in plants: from sequence and markers to chromatin and chromosomes. Plant Cell 12, 617-635.

Hubbell, H. R. (1985). Silver staining as an indicator of active ribosomal genes. Stain Technol. 60, 284-294.

Jimenez, M., Jimenez, R., Burgos, M. and Diaz de la Espine, R. (1988). A study of the Ag-staining significance in mitotic NORs. Heredity $\mathbf{6 0}, 125-$ 127.

Junera, H. R., Masson, C., Géraud, G., Suja, J. and Hernandez-Verdun, D. (1997). Involvement of in situ conformation of ribosomal genes and selective distribution of upstream binding factor in rRNA transcription. Mol. Biol. Cell 8, 145-156.

Kooter, J., Matzke, M. and Meyer, P. (1999). Listening to the silent genes: transgene silencing, gene regulation and pathogen control. Trends Plant Sci. 4, 340-347.

Leitch, A. R. (2000). Higher levels of organization in the interphase nucleus of cycling and differentiated cells. Microb. Mol. Biol. Rev. 64, 138-152.

Leitch, I. J. and Heslop-Harrison, J. S. (1992). Physical mapping of the 18s58-26s rRNA genes in barley by in situ hibridization. Genome 35, 10131018.

Leitch, A., Mosgller, W., Shi, M. and Heslop-Harrison, J. (1992). Different patterns of rDNA organization at interphase nuclei of wheat and rye. J. Cell Sci. 101, 751-757.

Mandrioli, M., Manicardi, G. C., Bizzaro, D. and Bianchi, U. (1999). NOR heteromorphism within a partenogenetic lineage of the aphid Megoura viciae. Chromosome Res. 7, 157-162.

Martini, G. and Flavell, R. B. (1985). The control of the nucleolus volume in wheat, a genetic study of three developmental stages. Heredity 54, 111120.

Matzke, A. and Matzke, M. (1998). Position effects and epigenetic silencing of plant transgenes. Curr. Opin. Plant Biol. 1, 142-148.

Matzke, M., Matzke, A. and Scheid, O. (1994). Inactivation of repeated genes- DNA-DNA interaction? In Homologous Recombination and Gene Silencing in Plants (ed. J. Paszkowski), pp. 271-304. The Netherlands: Kluwer Academic Publishers.

McClintock, B. (1934). The relationship of a particular chromosomal element to the development of the nucleoli in Zea mays. Z. Zellforch. Mikrosk. Anat. 21, 294-328.

Mellink, C. H., Bosma, A. A. and de Haan, N. A. (1994). Variation in size of Ag-NORs an fluorescent rDNA in situ hybridization signals in six breeds of domestic pig. Hereditas 120, 141-149.

Morais-Cecílio, L., Delgado, M., Jones, R. N. and Viegas, W. (1996). Painting rye B chromosomes in wheat: interphase chromatin, organization, nuclear disposition and association in plants with two, three and four Bs. Chromosome Res. 4, 195-200.

Morais-Cecilio, L., Delgado, M., Jones, R. N. and Viegas, W. (2000). Modification of wheat rDNA loci by rye B chromosomes: a chromatin organization model. Chromosome Res. 8, 341-351.

Neves, N., Silva, M., Heslop-Harrisson, J. S. and Viegas, W. (1995). rRNA gene activity and control of expression mediated by methylation and imprinting during embryo development in wheat $\mathrm{x}$ rye hybrids. Theor. Appl. Genet. 91, 529-533.

Pikaard, C. (1999). Nucleolar dominance and silencing of transcription. Trends Plant Sci. 12, 478-483.

Pikaard, C. (2000). Nucleolar dominance: uniparental gene silencing on a multi-megabase scale in genetic hybrids. Plant Mol. Biol. 43, 163-177.

Platero, J. S., Csink, A. K., Quintanilla, A. and Henikoff, S. (1998). Changes in chromosomal localization of heterochromatin-binding proteins during the cell cycle in Drosophila. J. Cell Biol. 140, 1297-1306.

Pluta, A., Mackay, A., Ainsztein, A., Goldberg, I. and Earnshaw, W. (1995). The centromere: hub of chromosomal activities. Science 270, 15911594.

Rawlins, D. J. and Shaw, P. J. (1990). Three-dimensional organization of ribosomal DNA in interphase nuclei of Pisum sativum by in situ hybridisation and optical tomography. Chromosoma 99, 143-151.

Robert-Fortel, I., Junéra, H. R., Géraud, G. and Hernandez-Verdun, D. (1993). Three-dimensional organization of the ribosomal genes and AgNOR proteins during interphase and mitosis in $\mathrm{PtK}_{1}$ cells studied by confocal microscopy. Chromosoma 102, 146-157. 
Roussel, P., Andre, C., Comai, L. and Hernandez-Verdun, D. (1996). The rDNA transcription machinery is assembled during mitosis in active NORs and absent in inactive NORs. J. Cell Biol. 133, 235-246.

Schwarzacher, T., Leitch, A., Bennettt, M. D. and Heslop Harrisson, J. S. (1989). In situ localization of parental genomes in a wide hybrid. Ann. Botany 64, 315-324.

Shaw, P., Rawlins, D. and Highett, M. (1993). Nuclear and nucleolar structure in plants. In The Chromosome (ed. J. S. Heslop-Harrisson and R. B. Flavell), pp. 161-171. Oxford: Bios Scientific Publisher.

Suzuki, H., Kusittara, Y., Kancisa, T. and Moriwaki, K. (1990). Variation in the distribution of the silver staining nucleolar organizer regions on the chromosomes of the wild mouse Mus musculus. Mol. Biol. Evol. 7, 271282.

Sybenga, J. (1983). Rye chromosome nomenclature and homeology relationships. Z. Pflanzenzuchtg. 90, 297-304.

Wallace, H. and Langridge, W. H. R. (1971). Differential amphiplasty and the control of ribosomal RNA synthesis. Heredity 27, 1-13.
Wolffe, A. and Matzke, M. (1999). Epigenetics: regulation through repression. Science 286, 481-486.

Zurita, F., Sanchez, A., Burgos, M., Jimenez, R. and Diaz de la Guardia, R. (1997). Interchromosomal, intercellular and interindividual variability of NORs studied with silver staining and in situ hybridization. Heredity $\mathbf{7 8}$, 229-234.

Zurita, F., Jimenez, R., Burgos, M. and Diaz de la Guardia, R. (1998). Sequential silver staining and in situ hybridization reveal a direct association between rDNA levels and the expression of homologous nucleolar organizer regions: a hypothesis for NOR structure and function. J. Cell Sci. 111, $1433-$ 1439.

Zurita, F., Jimenez, R., Diaz de la Guardia, R. and Burgos, M. (1999). The relative rDNA content of a NOR determines its level of expression and its probability of becoming active. A sequential silver staining and in situ hybridization study. Chromosome Res. 7, 563-570. 